\title{
Health inequities as a challenge to the social policies of European yovernments
}

\author{
Andrzej Wojtczak
}

Collegium Mazovia, Inovative University in Siedlce, Faculty of Health Science

Address for correspondence: Collegium Mazovia, Inovative University in Siedlce, Faculty of Health Science, Sokołowska 16,08-110 Siedlce,wojtczak@cmkp@edu.pl

\section{Abstract}

Health inequities are defined as systematic differences in health that can be avoided by appropriate policy intervention, and for this reason are considered unfair and unjust. Health inequities are not solely related to access to health care services; they are caused by the unequal distribution of these determinants of health, including power, income, goods and services, poor and unequal living conditions, and the differences in healthdamaging behaviours that these wider determinants produce. They are defined as systematic differences in health that can be avoided by appropriate policy intervention and that are therefore deemed to be unfair and unjust.

To be able to devise effective action, we first need to understand the causes of these inequities in health. Health inequities are not solely related to access to health care services; there are many determinants related to living and working conditions, as well as the overall macro-policies prevailing in a country or region.

The differences in social and economic development are reflected in health inequities that can be seen both between and within countries. Furthermore, evidence shows that even in the more affluent countries health inequities are seen in all parts of Europe. In the WHO European Region the gap in life expectancy between countries is 17 years for men and 12 years for women.

Inequities in health are caused by the unequal distribution of these determinants of health, including power, income, goods and services, poor and unequal living conditions, and the differences in health-damaging behaviours that these wider determinants produce.

The experiences of various countries indicates that in order to narrow the health inequities countries have to improve living conditions including the provision of comprehensive welfare systems, and high-quality education and health services.

The Strategy Health 2020 developed and approved by the WHO European Region countries is focusing on reducing inequities in health, which are key strategic objectives of endorsed by the 53 Member States. It emphasizes the need to strengthen population-based prevention on the social determinants of health. Also, in 2009 the European Commission developed European Union (EU) Health Strategy Programme titled "Solidarity in health: reducing health inequalities in the European Union".

\section{Key words: health inequities, health determinants, health policy, social policy, European Union \\ Stowa kluczowe: nierówności w zurowiu, polityka zurowotna, polityka spoteczna, Unia Europejska}

Ministerstwo Nauki Przygotowanie do wydania elektronicznego finansowane w ramach umowy

i Szkolnictwa Wyższego 637/P-DUN/2019 ze środków Ministerstwa Nauki i Szkolnictwa Wyższego przeznaczonych na działalność upowszechniającą naukę.

\section{Introduction}

Developed countries face various health challenges, one of the major ones being the inequities in health recorded among various social groups and conditioned by social and economic factors rather than biological causes. It should be emphasized that the occurrence of this type of 'health inequities' does not result from the lack of access to medical care, but is a consequence of state policies that do not serve to prevent the occurrence of social and economic differences between social groups, which is then reflected in their health. Therefore, they are the result of the socio-economic policy of the state and are contrary to the sense of justice understood as the human right to equal treatment of everybody's needs.

Inequities in health are particularly often found among socially disadvantaged people who have worse health, various disabilities and a shorter life span compared 
to groups of well-off people living in good conditions. Because these inequities can be avoided or reduced by the appropriate socio-economic policy of the state, they are therefore treated as unjustified, unfair and harmful.

The term 'inequities in health' in the context of health policy can be defined as differences in the state of health observed among individuals or social groups that are not the result of biological or genetic factors, but social and economic ones. Inequities in health occur both between different social groups and their members, as well as between citizens of different regions and states. It is not surprising, therefore, that in recent decades in many countries they have become the object of interest not only for people researching these issues, but also for politicians and governments of many countries. The causes of these 'inequities' are deeply rooted in various types of environmental, social and economic conditions affecting human health and referred to as 'health determinants'.

Presenting the report on inequities at the World Health Assembly, Sir Michael Marmot - Chairman of the Commission on Social Determinants of Health (CSDH) stated that "the main cause of inequities in health is the "deadly mix' of bad social policy and its programmes, and the unfair allocation of financial and material resources" $[1,2]$.

\section{Inequities in health - their essence and character}

The concept of 'health inequities' covers an incomparably wider spectrum of factors than equality in access to health services. It is about access to living conditions that allow one to stay healthy, and which are deeply rooted in various conditions such as education and income, housing, living and working environments, and applied health behaviours. These inequities occur both between different social groups and their members, as well as between different regions of the country and different states. They are the result of the social and economic policies of the state and values professed by those who govern it.

A study on the health of the population of Great Britain conducted by a team of researchers led by Sir Douglas Black had a major impact on stirring the interest of politicians and government institutions in the issue of inequities in health. The results included in the so-called Black Report [3], indicate that equality in access to medical services alone does not ensure health and that there is more to it, since it is down not only to biological, but also social and economic processes. No biological conditions would cause children from poor families to show twice the mortality rate as compared to children of rich people. The report postulated that these differences are the result of economic and social conditions of living and the social status of people or groups of populations that affect susceptibility to disease and life expectancy. Poor living conditions in infancy and childhood, and mainly insufficient nutrition, increase the risk of death and the number of cases of chronic noncommunicable diseases at a later age.

Therefore, the causes of health inequities are deeply rooted in various types of conditions such as living and working environments, economic conditions and health behaviours. Their size and intensity is influenced by the political system, which largely determines the social values and living conditions of citizens in a given country. The more liberal the system, the greater the social inequities and stratification, the result being work and living conditions that are not favourable to health. It is not surprising that they are not prevented simply by providing access to health services.

\section{Inequities in health - their definition and classification}

The concepts related to the occurrence and importance of inequities in health of the population were formulated in a document inspired by WHO and developed by Margaret Whitehead and Göran Dahlgren managing the WHO Centre for Research in Health Policy and Social Determinants at the University of Liverpool. It presents the assumptions of policies and strategies in this field to combat inequities in health which, translated into 20 languages, have been widely adopted in European countries and in North America. As stated in the document, inequities in health have two dimensions - moral and ethical ones. They refer to differences in health that are unjustified and unavoidable as well as unfair and harmful [4].

Therefore, in order to qualify a specific situation as causing a health inequity, it is necessary to classify its causes as 'unfair and harmful' in the context of the situation concerning social groups or the entire society. 7 differentiating health determinants can be used in this assessment:

1. Biological and natural factors.

2. Health-damaging and voluntary behaviour.

3. Transient inequalities between the group that has adopted healthy lifestyles and the group that is in the process of adopting them.

4. Health-damaging behaviour when choice is very limited.

5. Exposure to unhealthy, stressful living and working conditions.

6. Limited access to basic public services.

7. A natural decline on the social ladder associated with loss of health.

The first 3 items do not qualify as health inequities, while the next 3 meet the established criteria, because they could be avoided by providing adequate living and working conditions, and are therefore unfair. The situation mentioned in point 7 can be avoided by providing proper medical care; however, the ill usually cannot afford it, and so this situation is unfair and unjustified.

The basic test for determining injustice are situations that cannot be prevented from developing the disease due to a lack of knowledge of harmful environmental factors or lack of access to safe water. The goal of policies aimed at combating health inequities is to reduce or eliminate those factors that can be avoided and considered unfair. It is about creating conditions favourable to citizens' health. The problem of 'health inequities' has become one of the most important health and social policy goals of European countries, mainly Great Britain, Norway, Finland, Sweden and Germany [5].

Applying the commonly-used term 'mortality rate' to assess health inequities is burdened by the significant 
impact of the most common causes of human death such as heart attack, stroke, malignant tumors or respiratory failure, the severity of which is largely associated with living and working conditions. Moreover, the age of people at the time of death does not have to be interpreted as their state of health. Therefore, the most commonly used indicator is life expectancy. The use of the indicator 'average life expectancy at birth' provides information indicating the role of neonatal mortality, and 'life expectancy at age 65 ' provides information indicating the social and economic conditions of senior citizens. These indicators also allow comparisons between different regions and countries.

At the initiative of the World Health Organization, the 'Years of Healthy Life' and 'PYLL - Potential Years of Life Lost' indicators measured before the age of 70 , were introduced. They have gained quite a wide recognition because they allow for a more accurate analysis of the population's state of health.

\section{Socio-economic determinants and health}

Social and economic determinants cover a wide spectrum of factors such as education, employment, work place, professional position and income, or place of residence, and affect the modelling of behaviour and factors shaping the health of people and population groups. The effects of interaction between these factors and health in the context of the so-called socio-economic status (SES), are measured by morbidity and mortality rates. They are of a gradient character, i.e. people at the top of the SES hierarchy show better health and lower mortality than those who are situated below the top of this social ladder, especially at the very bottom. Where income differences are greater, members of the social community are more distant and there is a greater social and health stratification.

SES is the factor that shapes people's behaviour since early childhood and has a cumulative effect on both its quality and length. Behaviours are shaped by the atmosphere of the home and the environment and largely determine the educational aspirations that allow to acquire knowledge and qualifications. Starting one's life in conditions associated with worse social and economic status of parents increases the vulnerability to illness during childhood, and many diseases suffered during adolescence affect the vulnerability to illness and disability in later periods, which contributes to job loss, worsening their material situation. Therefore, the chances of maintaining health and work are associated with a good start in childhood, education, housing, satisfactory work and suitable earnings. It is also associated with leading a healthy lifestyle, and so avoiding stimulants, maintaining proper nutrition and exercising. On the other hand, low education contributes to less favourable health behaviours and poorer health. This selection based on the state of health causes the healthy individuals to move up the social ladder and gain better jobs and the patients fall down the ladder, which causes their social status to decline, i.e. the social or class gradient. An important factor are the relationships with other people and creating an environment of mutual support and consolidation of healthy behaviour. This relationship between the socioeconomic status and health status was observed in all countries where the study was conducted, which indicates that health is determined by material factors [6-8].

There is ample evidence that health inequality is directly linked to income, in particular the extent of poverty leading to social exclusion. Therefore, one of the main tasks of the government's health policy should be to reduce the effects of poverty and social inequities, since poverty is increasingly occurring in market economy conditions due to the economic stratification of society. This is happening not only in developing countries but also in the most developed ones.

\section{Inequities in health and the economic development of countries}

For a long time, health inequities were not perceived as a health risk factor and remained in the shadow of the government's undisputed priority of economic development. This was due to the conviction of mainly liberal economists that the increase in national income per capita and the growing wealth of the rich would ultimately benefit the whole society and lead to an improvement in the population's well-being. This belief caused that many countries entrusted matters of health to economic development, considered to be the driving force of progress in all areas of social life, including health, the indicator of which was to be the observed increase in the average life expectancy. This belief was supported by the observed decrease in the number of deaths in developed countries due to controlling the epidemic of infectious diseases and effective treatment of acute bacterial infections, rather than to improved living conditions.

It is not surprising that for a long time the occurrence of 'health inequities' was addressed as a problem of health care and the need to improve its activities. Their real causes and significance began to be slowly realized starting from the mid-twentieth century when a rapid increase was noted in the incidence of illness and death due to chronic non-communicable diseases referred to as lifestyle diseases - such as ischemic heart disease, stroke, lung cancer, cirrhosis, chronic lung diseases, as well as injuries and accidents. The list of various types of factors that contributed to their occurrence and growth went far beyond recognized biological factors and included various types of physical, chemical, environmental, social, behavioural and cultural factors. They have a direct or indirect effect on people's health. Over time, the list also included access to education and its level, access to work and earnings, as well as unemployment, poverty and social exclusion.

When in the early 1980s, attention was drawn to health inequities, the recipe for improvement was to achieve greater efficiency in healthcare. It was not understood then that the causes of these inequities were deeply rooted in various types of conditions such as health behaviour, environmental, social and economic conditions, referred to as 'health determinants' that affect people's health.

An example of such conditions was the research carried out in Scandinavian countries which showed that 
the poor population had more frequent cases of and deaths due to lung cancer, uterine cancer, chronic obstructive respiratory disease, perinatal complications as well as more frequent road accidents, more frequent alcoholism and suicides. Studies have also shown the incidence of coronary heart disease in men aged 25-74 to be more than twice in the group of people with basic education compared to people with higher education $[9,10]$.

It was slowly becoming more widely understood that the improvement of people's health in these situations should be part of the government's social policy and that it could not be expected only from the work of health care institutions.

\section{'Health inenuities' vs. the national income achieved}

Thanks to the work of Richard Wilkinson and Kate Pickett [11], the scope of discussion on existing health inequities was raised from the level of health assessment of individuals to the level of health assessment of social groups. According to research, health and social problems are more common and more widespread in lesswell-off social groups, and the severity of these problems is greater the greater are the inequities recorded in people's incomes. Where income differences are greater, members of the social community are separated by a greater distance and greater class stratification which plays a very important role in the emergence of health and social problems. They occur more often as the ladder of the social hierarchy goes down and are more often found in societies with greater income inequities.

The scale of these differences significantly affects the diversity of people's social status, which is also evident in their behaviour. These material disproportions are manifested in the way of dressing, the level of education, self-esteem, which is the reason for social divisions. In turn, the degree of income diversity of society significantly affects the health of citizens. As a measure of these inequities, differences in life expectancy of up to ten years can be observed. Therefore, building an egalitarian society has a positive effect on both the health of people and the economic growth of the country.

In the book titled The Spirit Level: Why More Equal Societies Almost Always Do Better (Duch równości) [11], Wilkinson and Pitchett point out that reducing material differences between people contributed to improving their health. The most egalitarian countries, not the richest, have the longest life expectancy of citizens. An example could be Greece, where even after taking into account the price difference, its citizen has an average income of more than half that of a US citizen but still enjoys better health. Japan can serve as an example where the process of reducing the income gap between citizens has been taking place for a long time and whose society has been characterized by the longest life expectancy in the world since the late 1980s.

Material differences are the foundation on which arise various social distinctions. Therefore, their reduction is an important remedy for improving the quality of life of citizens.

\section{Eductition of people and socio-economic development}

According to Wilkinson \& Pickett [11], the most commonly used indicator of the socio-economic status of individuals or families and determining their position and prestige is their education measured by the number of years of education and the titles obtained. The knowledge and skills acquired enable adequate employment and earnings that make available various goods and benefits. Education also has the greatest impact on people's health behaviour. Education allows the rational use of information, including health information, which increases the ability to strengthen the state of one's own health and influences the determination of the position of health in the hierarchy of life values of a given person. On the other hand, uneducated people, those who earn less and are many times unemployed, get sick more often, experience disabilities more often and their average life expectancy is shorter compared to those without material problems. Therefore, a well-functioning education system not only provides an inflow of qualified employees but also their professional development, higher material status and better health.

In the report on school education in Great Britain, the gap between children from poor and rich families was indicated as the biggest problem in teaching. Children coming from poor families and with uneducated parents do worse than children from wealthy homes where education is valued. The family environment and the 'social and cultural capital' brought out of the home have the greatest impact on children's mental development [12].

In Sweden, known for the widespread availability of health care and a well-functioning social security system, groups of poorly educated people with a worse life situation have higher mortality. In turn, research in France shows that the life expectancy of a 35-year-old academic teacher is 9 years longer than that of an unskilled worker of the same age, and studies in Estonia found that an educated man aged 25 could expect a 13-year longer compared to a man of the same age and no education [12].

\section{'Health inequities' in European countries}

A significant contribution to explaining the observed 'health inequities' was made by research conducted in Great Britain and the Scandinavian countries, based on the type of work performed by the respondents and their socio-economic status. The categorization of the respondents was reduced to a simple division into "occupations related to intellectual work" (social classes I-III a) and "occupations related to physical work" (social classes III $b-V)$. Using the above classification, it was found that in Great Britain the life expectancy at birth for the first class is about 9 years higher than for the fifth class. The life expectancy for men in social class I from the beginning of the 1970 s to mid-1990s increased from 72 to 77.8 years, while among men in social class V from only 66.5 to 68.2 years. It follows that over a 20 -year period, the difference in life expectancy between these classes increased from 5.5 to 9.5 years. In women, the differences in life expectancy were much smaller. 
In the light of research by Marmot the regularity of mortality depending on the social class suggests that influences other than polluted environment, unsafe work, or health behaviours that may explain various types of illness, must be at play here. While there is no doubt as to the health impact of risk factors such as smoking and alcohol abuse whose consumption is clearly related to social classes and dominant 'unhealthy' behaviours, differences in health at the top and bottom of the social ladder seem be associated with social and economic factors that increase susceptibility to disease. These studies played an important role in shifting the focus from 'unhealthy' behaviours of individual people to the broader concept of behaviours of specific social groups.

Research conducted in Great Britain under the direction of M. Marmot [2] on civil servants, the so-called Whitehall Study has shown the existence of a social gradient in health, which is measured by the frequency of sickness absence and deaths not related to harmful factors, unemployment or poverty. The risk of death from coronary heart disease, stroke, smoking-related cancer, gastrointestinal tract diseases, accidents and suicides was found to be 2.5 times higher for people in a lowerranking position.

The above observations confirm comparative studies of the mortality rate of people belonging to different social classes, conducted by Anton. Kunst et al. [13] in 11 European countries. They showed that the probability of death between 40 and 65 years of age for working-class men compared to white-collar workers was 5 to 7 years in Sweden, Norway, Denmark, England and Wales, Ireland, Italy, Spain and Portugal, and in the case of Finland and France, 9.8 and 11.5 years respectively. As a rule, in countries where there are ethnic minorities and numerous immigrant groups, higher mortality rates are usually recorded.

To visualize the extent of these inequities, it is worth mentioning that in the UK, the life expectancy of a child born in an intellectual family is 5 years longer compared to a child born in a working-class family, and in the poor districts of Glasgow a child born there lives on average 10 years shorter than a child born in a prosperous district of this city [14].

In a study carried out in Warsaw $[15,16]$ large differences in the average life expectancy between residents of different districts of Warsaw were found. And so the differences between men living in the Praga Północ District and the wealthy Wilanów were 14 years, and for women -19 years. These differences for residents of the Bielany and Żoliborz neighbouring districts (but of unequal wealth), in the case of men amounted to 6 years and for women -4 years. In addition to Wilanów, the districts with the highest life expectancy exceeding 82 years include Bemowo, Ursynów and Włochy, as well as Wesoła, Wawer and Ursus located near Warsaw.

Also in Hungarian studies it was found that the average life expectancy in the poor districts of Budapest is 4 years shorter than the national average, and 5.5 years shorter than for people from wealthy districts. In the United States, one of the richest countries in the world, despite the general wealth of the state, the problem of health inequities is visible among numerous groups of poor ethnic minorities and indigenous people of that continent. However, there is little interest in this problem, and the idea of equality of social classes in access to various types of goods is not widely accepted [17].

Therefore, actions aimed at reducing health inequities depend mainly on the political will of state authorities and the provision of financial resources and cooperation of all economic and social sectors., social organizations, local governments, state institutions and active participation of the interested parties.

\section{Health inequities during the transformation of the 1990s}

The relationship between the socio-economic status and health was very clearly marked during the political transformation of the 1990s in the countries of Central and Eastern Europe (CEE) and in countries that arose after the collapse of the Soviet Union (FSU countries). It was the cause of many crises and has contributed to the escalation of socio-economic disparities both within and between countries, and to increasing health inequities.

During this period, the "revealed truth" of free market economic programmes recommended by the World Bank and the International Monetary Fund constituted the so-called Kuznets curve stating that as the economy develops, inequality in society is inevitable, but in the long run rapid economic growth will make all citizens grow rich. However, the truth of this claim is doubtful, because when in the 1960s to the mid-1970s - during the so-called golden age of capitalism - in Western European countries the revenues of states grew threefold and in Japan eightfold faster than today, the observed social inequities were small.

It is worth adding that the welfare state system was created in the 1930s in Scandinavian countries, when there was great poverty in Northern Europe and the 'prescription' was the welfare state. In Scandinavian countries, the welfare state cooperates with the free market in the fight against poverty. There is a social insurance system, public health service, public education system, research and culture are financed - areas of social life that the free market is reluctant to finance. In Scandinavian societies, where the inequality is kept as low as possible, the rich and the less-well-off live better. The notion of the so-called 'social cohesion', which is associated with solidarity and collective consciousness, factors affecting the health of members of the community. It is more than just the sum total of the actions of individuals, but also a sense of social solidarity and collective consciousness, constituting a version of communitarianism - acting for the common good.

Another promoted theory was the so-called trickledown theory saying that if we leave more to the rich, they will spend this money on the development of enterprises, employ more employees, buy more goods and everyone will live better. According to Zygmunt Bauman, the conviction that the growing wealth of the richest citizens will ultimately benefit the entire society through the so-called trickle-down effect, supported by 
leaders of almost all political options, proved to be untrue. There is no relationship between the elite getting wealthy and the improvement of the safety and health of the whole society, and competition and consumption are the regulating factors in a free market economy. A wellfunctioning state should moderate these extremes. An example are the Scandinavian countries, where the free market economy does not interfere with the development of institutions and mechanisms of the welfare state.

\section{Health inequities in Poland}

In the 1990s Poland became notably wealthier and so did some of its citizens despite the absence of a regulatory role of the state. Although the life of a large part of society undoubtedly improved, the functioning of public institutions such as health care or railways became increasingly worse. The financial crisis of 2008, in turn, eroded people's confidence in the efficiency of the free market economy promised by politicians and economists to ensure a better material future for all citizens. This loss of faith translated into growing demands for the state to ensure the need for greater income equality and social security for citizens, including health care.

In a report based on population research on the occurrence of social inequities in health among children and adolescents living in Poland, Bogdan Wojtyniak and Joanna Mazur [15] confirm the relationship between their health condition and the material situation of their families, showing that it improves with the increasing level of the parent's education. A positive impact of parents' education level on the nutritional behaviour of the subjects and their lower exposure to second-hand smoke was also found. Although the risk of weight deficiency decreases among children of better educated parents, the number of overweight children increases. Studies have also shown that in the case of parents with higher education, children spend less time watching TV. The observed intensification of unfavourable differences in health behaviours of boys and girls is observed at the age of 12-13 years, which indicates the need to focus health promotion activities on this age group. School is an important place to implement programmes to level out differences in health.

Unfortunately, for a long time it has been getting increasingly difficult to access healthcare in Poland because of the long waiting times for benefits and their limitations, and so public healthcare must be supplemented with privately paid services. In Poland, over 2 million people have private insurance and even more use private health services in the event of an urgency. A similar situation applies to nurseries and kindergartens, childcare and education, which are supplemented by non-public institutions. In a situation of scarcity of social benefits, income becomes a crucial issue. For many women, the existing shortcomings of the social support system are an insurmountable barrier preventing them from maintaining a job or gainful employment supplementing family income. Poland allocates a lot of funds for social transfers, such as the " $500+$ programme" for each child or "13th pension", while insufficient funds are allocated for social benefits and the development of well-functioning social support systems. These deficiencies make for the weakness of our social policy and the related wage demands. This requires decisive action in these two policy areas, without which an improvement cannot be expected in the social situation of people and their satisfaction with the benefits of state institutions.

It is of fundamental importance to increase the professional activity of Poles, which differs from the recorded professional activity of people in other European countries. It is necessary to remove all barriers limiting work opportunities, such as prohibition of work to be performed by carers of disabled persons who receive benefits, or the income threshold for receiving child benefits.

The area requiring rapid improvement is the situation of the disabled, in particular the improvement of services supporting their independence and professional activity without which they are excluded from social life. Also, an area requiring rapid action is the provision of adequate living conditions for the elderly, especially women in order to prevent their pauperization at an advanced age. Awareness that the pension system is becoming inefficient and will not be able to provide social protection that would enable them to live a decent life should contribute to a wide-ranging discussion on its reform including all possible interested partners. This will avoid the necessity to impose solutions implemented at an accelerated pace and poorly adopted by those interested.

In view of the prolonged life expectancy, a thorough discussion of the retirement age is necessary. The system should support those who want to work longer, which requires adjustment of working conditions for them; also, there should be a system of vocational adjustment of seniors taking into account their individual capabilities and progressive phasing out of their professional activity.

\section{Health inequities in the programmes of the World Health Organization and the European Union}

Problems of social inequities in health would remain underestimated by the governments of developed countries were it not for the decisive positions of the World Health Organization and the European Union, for which the problem of health inequities as an important cause of unsatisfactory health of various social groups became one of the main challenges for the social policies of these Organizations.

According to data presented by the European Regional Office of the WH, in member states, the differences in life expectancy at birth between the countries of the region amount to the average 16 years (women 12 years, men -20 years). They are conditioned by differences in the social and economic status of population groups, among which the most disadvantaged are immigrants and seasonal workers. The occurring social inequities in health are one of the biggest health challenges in almost all countries of the European Region. It should be added that besides the social inequities 
in health, we also observe restrictions on the availability of basic health services. Factors limiting this availability are: the remote location of the facilities, the lack of family doctors, the lack of specialist doctors, and recently, the growing costs of services exceeding the financial capabilities of the payer, even in the wealthy regions of Europe. In the European Strategy of the WHO titled "Health 2020" the problem of health inequities has become one of the main directions of the Organization's activities. Among the four priority tasks, the WHO mentions "reducing inequities in health" in the Member States as an indispensable factor in the health of people, families and local communities.

The problem of health inequities is also a priority for the European Union, as research indicates a widening gap in the state of health of many social groups in European countries. Statistical data presented by Eurostat show that the difference in life expectancy at birth for women between EU countries is around 9 years, and for men - 14 years. In turn, infant mortality ranges from 3 to over 10 in 1000 life births...

In general, the inhabitants of Central and Eastern European countries live shorter compared to the EU average and spend more years in illness. Generally, less educated people with lower wages and harder working conditions die at a young age, showing many health problems from an early age. The differences in the expected average life expectancy at birth between people from low and high socio-economic status ranged from 4 to 10 years for men and from 2 to 6 years for women.

In 2009, the European Commission adopted the document "Solidarity in health: reducing health inequalities in the European Union" [18] indicating that reducing these inequities is a condition for improving the health of societies. This problem is also included in the European Health Strategy, which expresses the belief that the basic condition for improving the health of European citizens is to reduce 'social inequities', a condition for extending the life expectancy of healthy citizens. The reality of this goal can be demonstrated by the fact that in Sweden the inequities in infant mortality have almost been eliminated. Important factors causing differences in the state of health are working conditions and earnings, with the leading role being played by education as well as ethnicity. The European Union's "Closing the Gap" [5] programme is a strategy of actions aimed at combating inequities in health observed both between and within EU member states. The type of actions taken and information on differences in the state of health of citizens of different countries and social groups are published on a special EuroHealthNet portal [19].

\section{References}

1. Marmot M., Fair Society, Healthy Lives: Strategic Review of Health Inequalities in England Post-2010, Marmot Review London, University College, London 2010.

2. Marmot M., Davey Smith G., Stansfeld S. et al., Health inequalities among British social servants: the Whitehall II Study, "Lancet" 1991; 3 (37): 1387-1393.
3. Black D., Inequalities in health. The Douglas Black Report: A summary, "Intern. J. of Health Services" 1982; 12 (3): 349-380.

4. Dahlgren G., Whitehead M., European Strategies for Tackling Social Inequities in Health: Levelling up Part 2, World Health Organization Regional Office for Europe, 2006; http://www.euro.who.int/_data/a sets/pdf file/0018/103824/E89384.pdf?ua=1 (accessed: 20.05.2019).

5. Closing the Gap: Strategies for Action to tackle Health Inequalities in Europe. A European project from 2004 to 2007. Final Report (1.06.2004-31.05.2007). Grant Agreement Reference No. 2003318; https://neaygeia.gr/wp/ wp-content/uploads/2017/06/2003_3_15_frep_en.pdf (accessed: 03.06.2019).

6. Mackenbach J.P., Bakker M.J., Tackling socioeconomic inequalities in health: Analysis of European experiences, "Lancet" 2003; 362: 1409-1414.

7. Mackenbach J.P., Stirbu I., Roskam,A.J. et al., Socioeconomic inequalities in health in 22 European countries, "New England Journal of Medicine" 2008; 358: 2468-2481.

8. Majer I.M., Nusselder W.J., Mackenbach J.P., Kunst A.E., Socioeconomic inequalities in life and health expectancies around official retirement age in 10 Western-European countries, "Journal of Epidemiology and Community Health" 2011; 65: 972-979.

9. Lahelna E., Lundberg O, Manderbacka K., Roos E., Changing health inequalities in the Nordic countries? "Scand. J. of Public Health" 2001; 29 (Supll 55): 1-5.

10. Lundberg O., How do Welfare Policies contribute to the reduction of health inequalities, "Eurohealth" 2009; 5 (3): 24.

11. Wilkinson R., Pickett K., The Spirit Level: Why More Equal Societies Almost Always Do Better, Allen Lane, London 2009. Polish translation: Duch równości, transl. J.P. Listwan, Wydawnictwo Czarna Owca Sp. z o.o., Warszawa 2011.

12. Stirbu I., Kunst A.E., Bopp M., Leinsalu M., Regidor E., Esnaola S. et al., Educational inequalities in avoidable mortality in Europe, "J. Epidemiol. Community Health" 2010; 64: 913-920.

13. Kunst A.E., Groenhof F., Mackenbach J.P., Mortality by occupational class among men 30-64 years in 11 European countries. EU Working Group on Socioeconomic Inequalities in Health, "Soc. Sci. Med." 1998; 46 (11): 1459-1476.

14. Acheson E.D., Edwin Chadwick and the world we live in, "Lancet" 1990; 15.

15. Wojtyniak B., Mazur J. (eds.), Społeczne nierówności $w$ zdrowiu dzieci $i$ młodzieży w Polsce w świetle badań populacyjnych, Narodowy Instytut Zdrowia Publicznego PZH, Warszawa 2016.

16. Marek M., Chłoń-Domińczak A., Społeczne nierówności $w$ zdrowiu $w$ Polsce, World Health Organization (Biuro Światowej Organizacji Zdrowia w Polsce), Warszawa 2012.

17. Jagger C., Gillies C., Moscone F. et al., Inequalities in healthy life years in the 25 countries of the European Union in 2005: A cross-national meta-regression analysis, "The Lancet" 2008; 372: 2124-2131.

18. Xavier A., Price Ch., Nordheim von F., Solidarity in health. The European Commission sets out new actions on health inequalities, "Eurohealth" 2009; 5 (3): 7.

19. EuroHealhNet, European Partnership for Improving Health Equity and Wellbeing; https://eurohealthnet.eu/ (accessed: 08.06.2019). 